\title{
Time for an Undergraduate Curriculum in General Practice for Nepal
}

\author{
Butterworth K,' Pradhan R' \\ 'Department of General Practice and Emergency Medicine, Patan Academy of Health Sciences, Lalitpur, Nepal.
}

\section{ABSTRACT}

Introduction: This is a qualitative study, to generate a framework for a core curriculum in General Practice in the undergraduate setting, designed specifically for Nepal.

Methods: A Delphi process was used to involve representatives from the GP faculty in Institute of Medicine, BP Koirala institute BPKIHS, Patan Hospital/National Academy Medical Sciences and Tansen mission hospital. The Delphi involves getting input from an identified group of experts and progressively feeding back the results from each round of enquiry so that subsequent views are influenced until a point of convergence is reached. In effect the Delphi not only analyses problems and identifies solutions, but can begin the process of commitment to change.

Results: A prioritized list of the key outcomes for an undergraduate GP curriculum was developed and a broad list of knowledge, skills and attitudes were defined. A balance was observed between the need to train doctors who are skilled in communication, who have compassion for their patients, who are also required to be excellent rational clinicians able to respond to emergency situations. There was also the need for doctors to be competent not just in individual clinical care, but in the care of communities.

Conclusions: General Practice, as a core component of primary care, should be an obligatory part of every undergraduate medical curriculum. This Delphi process has produced an important framework for a national undergraduate curriculum in General Practice, designed specifically for Nepal.

Keywords: curriculum, delphi technique, education medical undergraduate, family practice, needs assessment

\section{INTRODUCTION}

The importance of family medicine has been acknowledged ever since the Alma Ata declaration in 1978 made primary health care an essential component of an efficient health care system. ${ }^{1}$
Deployment of well-trained and motivated General Practitioners is vital to build up the failing health care system in rural Nepal. This is unlikely to happen without fundamental changes in Nepal's medical education system. Exposure to the field of General Practice during the undergraduate curriculum is a critical step in recruitment of doctors to this discipline. ${ }^{2}$

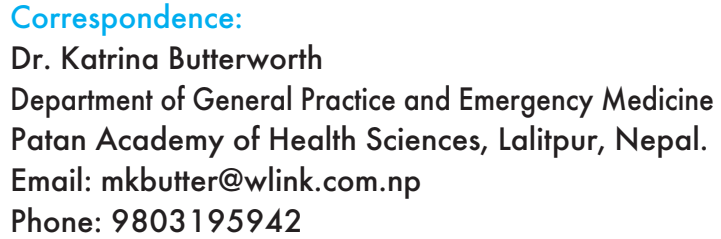


Butterworth et al. Time for an Undergraduate Curriculum in General Practice for Nepal

The aim of this study was to generate a framework for a core curriculum in General Practice in the undergraduate setting, designed specifically for Nepal. This may be used as a national resource for any medical school wishing to set up an undergraduate course in General Practice.

\section{METHODS}

This was a qualitative study conducted in Department of General Practice and Emergency Medicine, Patan Hospital, Lalitpur, Nepal from Jan to Jun, 2008. The Delphi process was used to explore the breadth and depth of what should be taught in an undergraduate curriculum in General Practice, as well as to generate a consensus on what the key competencies should be. $^{3}$ It was undertaken by email and paper based questionnaires.

There was purposive sampling of twenty-five General practitioners, representatives from the GP faculty in the three institutions that currently train post-graduate General Practitioners in Nepal (Institute of Medicine, BP Koirala institute BPKIHS and Patan Hospital/National Academy Medical Sciences), as well as experienced Nepali and expatriate General Practitioners working in a training role in Tansen mission hospital.

Each of the participants was sent an email or letter asking them to address the following questions:

What are the key things (objectives) we would want newly qualified medical students to know about General Practice/Family medicine?

What are the key skills we would expect them to achieve?

What attitudes would we expect them to develop?

Included in the initial mailing was a copy of the main objectives of the BPKIHS undergraduate curriculum for Family medicine as this is the only place where family medicine is currently taught to medical students in Nepal. A copy of the core objectives and competencies for postgraduate GP training in a rural district general hospital was also attached. ${ }^{4}$ These were intended to help stimulate thinking, but not to be proscriptive.

A Delphi process consists of four main stages from the perspective of the participants (Figure 1). At each stage, any participant who didn't respond in the first two weeks was then sent a reminder by email or post.

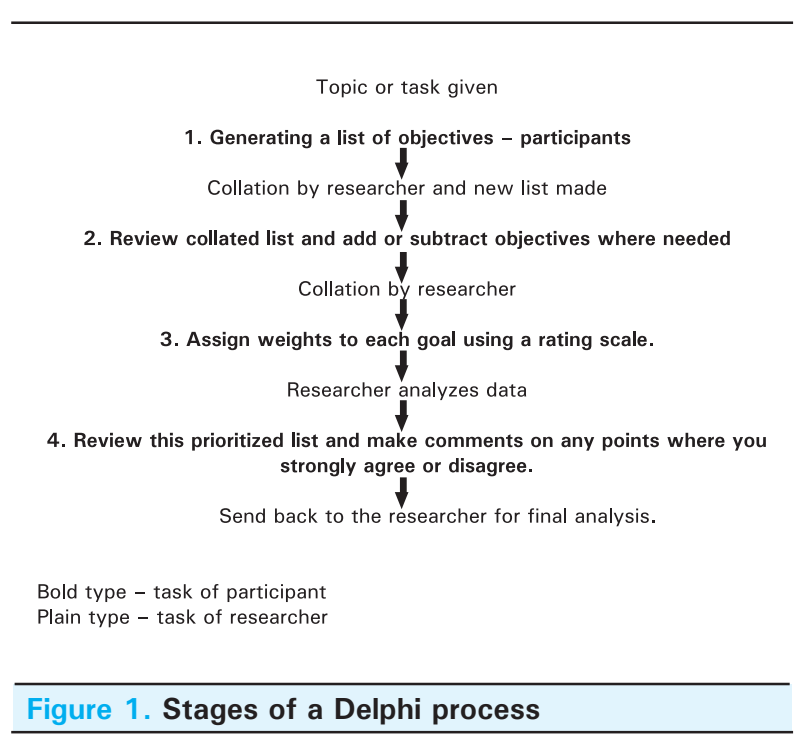

Two researchers independently reviewed the list of objectives generated by the group in step one, and identified common themes. Differences of opinion were noted. These themes were collated into a second list that was sent back to participants for review and comments. At this point participants have the opportunity to review the opinions of the whole group and can change their input or add new thoughts, stimulated by the document.

Once comments from step two were received, a further collated list was drawn up and participants were asked to assign weights to each objective using a rating scale of between 0 and 3 , where 0 was "no value" and 3 was "essential"(step three). The researcher then analyzed this data using a simple Excel spreadsheet. Mean values for each objective developed in the areas of Knowledge, Skills and Attitudes were calculated, giving a score between 0.0 and 3.0. It was then possible to rank order by mean rating, each of the objectives under the key headings of Knowledge, Skills and Attitudes.

\section{RESULTS}

Twenty participants responded to the first part of the Delphi process, while sixteen contributed to the final ranking of the areas identified. Tables one, two and three give the final results, ranking key competencies under each of the headings of Knowledge, Skills and Attitudes. The rank order is given, together with the mean score generated by each item.

Some of the areas identified were generic to general practice worldwide, while others were very specific to the role that general practice has in Nepal.

Under the area of knowledge, the first priority was for undergraduates to be able to describe the place of General Practice in the community and Nepal's national health care system, both urban and rural. 
Butterworth et al. Time for an Undergraduate Curriculum in General Practice for Nepal

Table 1. Key areas of Knowledge for Undergraduates in General Practice

\begin{tabular}{|c|c|c|}
\hline $\begin{array}{l}\text { Rank } \\
\text { order }\end{array}$ & Mean score & Key areas of Knowledge \\
\hline 1 & 2.5625 & $\begin{array}{l}\text { Describe the place of GP in community and Nepal's national health care system } \\
\text { both urban and rural } \\
\text { for all age groups }\end{array}$ \\
\hline 2 & 2.4375 & Describe the key health problems in the Nepal context \\
\hline 3 & 2.3125 & $\begin{array}{l}\text { Explain the role of Health promotion and disease prevention both individually and at population } \\
\text { level }\end{array}$ \\
\hline 4 & 2.25 & Discuss the importance of continuity of care, especially in chronic disease \\
\hline 4 & 2.25 & Understand the principles of critical thinking and Evidence based practice \\
\hline 5 & 2.2 & Describe how society family/socio-economic and cultural issues impact on health \\
\hline 6 & 2.0625 & Discuss the theoretical concept of General Practice as a specialty \\
\hline 7 & 2.0 & $\begin{array}{l}\text { Discuss the link between primary, secondary and tertiary levels of care with appropriate } \\
\text { referral and systems for review }\end{array}$ \\
\hline 8 & 1.75 & Discuss the role of Research in primary care \\
\hline 9 & 1.6875 & Discuss the particular role of the GP in the management of the elderly and dying. \\
\hline
\end{tabular}

Other important areas included a familiarity with conditions important in the context of Nepal and concepts such as health promotion and continuity of care. General Practice incorporates not just good individual clinical care, but care of communities. In General Practice, doctors are encouraged to treat people holistically, considering their cultural and socio-economic constraints, rather than in a disease-orientated fashion.

Table 2. Key skills for undergraduates in GP

\begin{tabular}{|c|c|c|}
\hline $\begin{array}{l}\text { Rank } \\
\text { order }\end{array}$ & Mean score & Key skills \\
\hline 1 & 2.75 & Demonstrate good communication skills \\
\hline 1 & 2.75 & $\begin{array}{l}\text { Recognize a seriously ill patient (airway, breathing or circulation compromise) and start } \\
\text { initial emergency care }\end{array}$ \\
\hline 2 & 2.5625 & $\begin{array}{l}\text { Make a rational initial differential diagnosis with efficient appropriate use of investigations, } \\
\text { rational prescribing and development of a treatment plan. }\end{array}$ \\
\hline 2 & 2.5625 & Demonstrate Good team work and communication within the team \\
\hline 3 & 2.5 & Perform a Targeted, focused physical examination \\
\hline 4 & 2.4667 & Perform triage in a trauma situation \\
\hline 5 & 2.4375 & Perform initial assessment and stabilization of a trauma patient \\
\hline 5 & 2.4375 & $\begin{array}{l}\text { Demonstrate a patient-centred holistic approach } \\
\text { Taking into account how social, cultural and psychological factors influence the way a } \\
\text { patient experiences and deals with ill health }\end{array}$ \\
\hline 6 & 2.3125 & Give health education in a patient-centred manner \\
\hline 7 & 2.25 & Demonstrate an Evidence based approach to their clinical work \\
\hline 7 & 2.25 & Make Decisions regarding patient care \\
\hline 7 & 2.25 & Arrange appropriate Follow-up and referral \\
\hline 8 & 2.125 & Involve patients and family in the management plan \\
\hline 8 & 2.125 & Recognize the indications for intubation and perform intubation \\
\hline 9 & 2.0625 & Implement appropriate screening \\
\hline 9 & 2.0625 & Work efficiently with limited resources \\
\hline 9 & 2.0625 & Demonstrate a Logical Problem orientated approach to undifferentiated presentations \\
\hline 10 & 2.0 & $\begin{array}{l}\text { Work (as a leader) as part of a primary health care team particularly in a community } \\
\text { setting }\end{array}$ \\
\hline 10 & 2.0 & Demonstrate Leadership and management skills \\
\hline
\end{tabular}


Butterworth et al. Time for an Undergraduate Curriculum in General Practice for Nepal

\begin{tabular}{lll}
\hline 11 & 1.9375 & Use time as a diagnostic tool \\
11 & 1.9375 & Perform certain basic surgical, orthopaedic and obstetric procedures \\
12 & 1.875 & Demonstrate Good teaching skills \\
13 & 1.6875 & Deal with issues surrounding death and dying \\
\hline
\end{tabular}

A wide range of skills were identified as being important to the undergraduate in their exposure to General Practice. These included both "soft" skills of communication and patient-centredness, together with acute emergency management skills.

Some skills and knowledge that were identified in the initial stage of the Delphi process were later ranked as being of lesser importance, mainly because they were seen as being more in the realm of postgraduate studies.

Table 3. Key attitudes for undergraduates in GP
These included palliative care, research, teaching skills, surgical and obstetric procedures as well as leadership and management skills.

The final broad area that was examined in this Delphi process was that of the attitudes we would want our medical students to develop during their undergraduate course in General Practice. The key attitudes identified are listed in rank order in Table 3.

\begin{tabular}{lll}
\hline $\begin{array}{c}\text { Rank } \\
\text { order }\end{array}$ & Mean scores & \multicolumn{1}{c}{ Key attitudes } \\
\hline 1 & 2.75 & Commitment to serve the poor and underprivileged in Nepal \\
2 & 2.6875 & Self-awareness including awareness of own limitations for appropriate referral \\
3 & 2.625 & Respect for all patients and holistic approach \\
3 & 2.625 & Compassionate approach to all patients \\
3 & 2.625 & Collaborative approach to working in a team \\
4 & 2.5625 & Professional integrity, including confidentiality and ethical work practices \\
4 & 2.5625 & Critical thinking, reflective practice and commitment to life-long learning (professionalism) \\
\hline
\end{tabular}

All participants scored these attitudes very highly. Again, while some of these attitudes would be generic to General Practice and other medical specialties worldwide, others are more specific to Nepal.
The final table (table 4) gives a prioritized list of the key areas identified from Knowledge, Skills and Attitudes that achieved a mean score of 2.5 or greater out of a maximum of 3.0. Interestingly, all seven of the "attitudes" are included in this table.

Table 4. Areas reaching highest overall priority (receiving a score of $>2.5$ out of 3.0 )

\begin{tabular}{|c|c|c|}
\hline $\begin{array}{l}\text { Rank } \\
\text { order }\end{array}$ & $\begin{array}{l}\text { Mean } \\
\text { score }\end{array}$ & Area \\
\hline 1 & 2.75 & Commitment to serve the poor and underprivileged in Nepal \\
\hline 1 & 2.75 & Demonstrate good communication skills \\
\hline 1 & 2.75 & $\begin{array}{l}\text { Recognize a seriously ill patient (airway, breathing or circulation compromise) and start initial } \\
\text { emergency care }\end{array}$ \\
\hline 2 & 2.6875 & Self-awareness including awareness of own limitations for appropriate referral \\
\hline 3 & 2.625 & Collaborative approach to working in a team \\
\hline 3 & 2.625 & Respect for all patients and holistic approach \\
\hline 3 & 2.625 & Compassionate approach to all patients \\
\hline 4 & 2.5625 & $\begin{array}{l}\text { Make a rational initial differential diagnosis with efficient appropriate use of investigations, } \\
\text { rational prescribing and development of a treatment plan. }\end{array}$ \\
\hline 4 & 2.5625 & Demonstrate Good team work and communication within the team \\
\hline 4 & 2.5625 & Professional integrity, including confidentiality and ethical work practices \\
\hline 4 & 2.5625 & Critical thinking, reflective practice and commitment to life-long learning (professionalism) \\
\hline 4 & 2.5625 & $\begin{array}{l}\text { Describe the place of GP in community and Nepal's national health care system } \\
\text { both urban and rural } \\
\text { for all age groups }\end{array}$ \\
\hline 5 & 2.5 & Perform a Targeted, focused physical examination \\
\hline
\end{tabular}


Butterworth et al. Time for an Undergraduate Curriculum in General Practice for Nepal

The balance is observed again for the need to train doctors who are skilled in communication, who have compassion for their patients, who are also required to be excellent rational clinicians able to respond to emergency situations.

\section{DISCUSSION}

While the place of the General Practitioner is internationally recognized as a key part in the provision of good primary health care, ${ }^{1}$ there is limited political acknowledgement of this role in Nepal. This has led to an emphasis on specialist tertiary level care within medical schools and also in the health care system, with concomitant lack of commitment to primary health care and limitation of access to good health care for the vast majority living in rural Nepal.

In a report published by the World Health Organization in January 2004, reviewing international studies on restructuring health care, it was concluded that the strength of a country's primary care system is associated with improved population health outcomes for all-cause mortality. Health systems in low income countries with a strong primary care orientation tend to be more propoor, equitable and accessible. ${ }^{5}$

The reality in Nepal is that almost $90 \%$ of Nepal's doctors operate only in the cities and yet nearly $90 \%$ of Nepal's population lives in rural areas. This leads to wide disparities in the number of patients for which one doctor is potentially responsible. In the Kathmandu Valley, there is a ratio of one doctor / 4,527 people compared to one doctor $/ 24,701$ people nationally (Nepal District Health Profile 2007). ${ }^{6}$ In remote mountainous areas there are even fewer medical professionals per head of population. This problem is compounded by the increasing trend of migration of doctors and nurses abroad. Orientation of young doctors to the principles and role of General Practice, specific to Nepal, is one strategy to try and address this imbalance.

Internationally, General Practice and primary care is increasingly recognized as a vital part of both undergraduate and postgraduate medical training. Just as the health care needs in different countries differ, so the design of the medical curriculum must vary to meet that nations requirements.

In the United Kingdom, in response to the recommendations of the General Medical Council in "Tomorrow's doctors" (2003), academic departments of general practice are increasingly involved in teaching both general practice and general medical skills at undergraduate level. Curriculum change is occurring rapidly, with an increasing trend towards community teaching. ${ }^{7}$ Similarly General Practice is an integral part of the undergraduate curriculum in the University of
Otago, Christchurch, New Zealand. All medical schools in Australia, now have a General Practice department.

This study has produced a comprehensive blueprint for an undergraduate curriculum in General Practice, designed specifically for Nepal.

Under the heading of "Knowledge" the first priority was for undergraduates to be able to describe the place of General Practice in the community and Nepal's national health care system, both urban and rural. This reflects a major concern that the vast majority of doctors currently practicing in Nepal, as well as the majority of the ordinary population, have no idea what "General Practice" is. ${ }^{8}$

Review of the key areas of Knowledge and Skills, shows the almost equal emphasis put upon the widely differing principles of health promotion and chronic care, hand in hand with acute management of the critically ill. This reflects the particular role of the General Practitioner in Nepal, where they are often the most senior doctor in a rural hospital, with both public health responsibilities and clinical duties. In the city, GPs usually take on the role of running the Emergency Department in a hospital. Many newly qualified MBBS doctors will be sent to rural hospitals, where they may be the only doctor. A good grounding in the principles of General Practice, as outlined in this curriculum will help prepare them to provide excellent health promotion and disease prevention, in addition to the confidence to manage seriously ill patients.

One of the key findings of this study is the high priority set on developing appropriate attitudes amongst medical students. This is obviously not the sole remit of General Practice but needs to permeate through the whole of the medical school curriculum, including the "hidden curriculum" provided by the attitudes of faculty and role modeling done by teachers.

It is interesting too, to see the importance that has been assigned to professionalism generally - an area that seems to be neglected amongst medical schools within Nepal at present. Using an "outcome based" approach to the development of this curriculum has enabled a broader and more comprehensive framework. This has been clearly described in the literature. ${ }^{9}$

Nepal remains a very poor country, with a Human Development Index ranking of 138 and a gross domestic product of just $\$ 1,490$ per capita. Thirty percent of the population live below the poverty line. ${ }^{10}$ Most medical care in Nepal is focused on the cities, where the majority of doctors work. Most of the population lives in poor areas of the terai and middle hills. Generating a sense of commitment to these people, as well as a compassionate and holistic approach (considering 
socioeconomic and cultural factors during management) will be key to addressing the health care needs of the nation.

\section{CONCLUSIONS}

Good primary health care, of which General Practice is a core component, is recognized to be the key to achieving better health. We contend that General Practice should be a required part of every medical undergraduate curriculum in Nepal.

This Delphi process has produced a framework for a national undergraduate curriculum in General Practice, designed specifically for Nepal. It is meant not to be proscriptive but to stimulate thought and provide structure for those wanting to better meet the health care needs of Nepali citizens. The details of how these curriculum objectives are met will vary with each medical school.

\section{ACKNOWLEDGEMENTS}

We would like to thank all those General Practitioners who participated in the Delphi process, contributing their time, energy and expertise towards developing this curriculum.

\section{REFERENCES}

1. Heath I. A General practitioner for every person in the world. BMJ. 2008;336:861.

2. Hayes B, Butterworth K, Neupane B. Recruitment of General practitioners in Nepal. Middle East J Family Med. 2008 Aug;6(6):17-21.

3. Lawrence PF, Alexander RH, Bell RM, Folse R, Guy JRF, Haynes JL, et al. Determining the content of a surgical curriculum. Surgery. 1983;94(2):309-17.

4. Butterworth K. Needs Assessment for Medical Education in Rural Nepal. Newsletter of Towards Unity for Health. 2006;25(2):17.

5. Haslam D. The best of both worlds: How Primary care can save lives and money. Malta Medical Journal. 2008;20(1):5-7.

6. Nepal District Health Profile. EHA 22. Kathmandu: DOHS; 2007 Dec.
7. Robinson LA, Spencer JA, Jones RH. Contribution of academic departments of general practice to undergraduate teaching, and their plans for curriculum development. Br J Gen Pract. 1994 Nov;44(388):489-91.

8. Butterworth K, Hayes B, Neupane B. Retention of general practitioners in rural Nepal: A qualitative study. Aust J Rural Health. 2008;16:201-6.

9. Harden RM, Davis MH. The core curriculum with options or special study modules. Scotland, UK: AMEE Education Guide; 1995. 